\title{
Impacto glocal de Bandung a la Iniciativa Belt and Road: Flujos de materiales, energías y humanos y sus efectos en la (in)justicia socioambiental en China
}

\author{
Chiara Olivieri*
}

\section{RESUMEN}

El objetivo de este trabajo es el de investigar el impacto de la Iniciativa Belt and Road (BRI) en la apropiación de materiales y energía en la Región Autónoma Uigur de Xinjiang (XUAR) de la República Popular de China (RPCh) Para ello, propongo un análisis contrastivo crítico de las narrativas historiográficas oficiales: narrativas sobre la inclusión oficial del territorio conquistado de la Región Autónoma Uigur de Xinjiang en las fronteras del Imperio Qing en el siglo XVIII; el Comunicado Final de la Conferencia de Bandung; los discursos modernizadores impuestos por la República Popular de China en el territorio de XUAR a través de las narrativas desarrollistas que acompañan la BRI.

Los sistemas socioambientales autóctonos han sido sometidos, desde la inclusión del territorio en las fronteras chinas, a mecanismos de colonialismo implementados por agentes externos. Este proceso ha dado lugar a un conflicto interétnico y a un proceso de gentrificación de los territorios resultante de un modelo extractivista y capitalista de gestión de los recursos naturales (agricultura, gas, petróleo). La BRI, basada en el desarrollo de las infraestructuras de transporte y logísticas, refleja una estrategia que tiene como objetivo promover el papel de la República Popular de China en las relaciones globales: potencia los flujos de inversión internacional y las salidas comerciales para los productos chinos, a través de rutas terrestres y marítimas, tratando de restablecer las antiguas Rutas de la Seda, y promueve la creación de nuevas carreteras, con el fin de conectar un mayor número de territorios y países —alrededor de sesenta—.

En cambio, esta investigación tiene como propósito el de revelar el impacto de la imposición del modelo económico y extractivo neocolonialista de la RPCh, así como sus consecuencias futuras sobre las poblaciones indígenas y los modelos autóctonos de gestión. En términos de metodología, esto requiere reconstruir las narrativas de pobreza del pueblo uigur, incluyendo relatos de su exclusión, expulsión de sus tierras originarias proponiendo un especial énfasis en la mirada autóctona sobre su entorno y cómo la Modernidad invade su espacio natural y humano.

\section{Palabras clave}

Xinjiang; Uigur; BRI; Bandung; conflictos socioambientales.

* Chiara OLIVIERI, Doctora en Estudios Migratorios por la UGR (España), Investigadora Postdoctoral Asociada en el proyecto "Islamophobia in the East of the European Union" (Toronto). Su principal línea de investigación actual es investigación decolonial aplicada al caso del pueblo uigur en la República Popular de China y en la diáspora. Contacto: olivie-ric@ ugr.es

Recibido:

1 2.08.2020

Aceptado:

22.03.2021

\section{Title}

Glocal Impact from Bandung to the Belt and Road Initiative: Material, energy and human flows and their effects on Socio-Environmental (in)justice in China

\section{EXTENDEd Abstract}

The aim of this article is to investigate the impact of the Belt and Road Initiative (BRI) on the appropriation of materials and energy in XUAR (PRC). To do this, I propose a critical contrastive analysis of official historiographical narratives: narratives about the official inclusion of the conquered territory of the Uyghur Autonomous Region of Xinjiang (XUAR-PRC) at the borders of the Qing Empire in the 18th century; the Final Communiqué of the Bandung Conference; the modernizing speeches imposed by the PRC on the territory of XUAR through the developmental narratives that accompany the BRI.

The autochthonous socio-environmental systems have been subjected, since the inclusion of the territory into the Chinese borders, to mechanisms of colonialism implemented by external agents. This process has given rise to an interethnic conflict and a process of gentrification of the territories resulting from an extractivist and capitalist model of natural resource

DOI:

https://doi.org//0.15366/relacionesinternacionales2021.47.012

Formato de citación recomendado:

OLIVIERI, Chiara (2021). "Impacto glocal de Bandung a la Iniciativa Belt and Road: Flujos de materiales, energías y humanos y sus efectos en la (in)justicia socioambiental en China”, Relaciones Internacionales, n 47, pp. 237-256. 
management (agriculture, gas, oil). The BRI, based on the development of transport and logistics infrastructures, reflects a strategy that aims to promote PRC's role in global relations: it enhances international investment flows and commercial outlets for Chinese products, through land and sea routes, trying to reestablish the ancient Silk Roads, and promotes the creation of new roads, in order to connect a wider number of territories and countries - around sixty-

In turn, this research aims to reveal the impact of the imposition of the PRC neo-colonialist economic and extractive model, as well as the future consequences, on indigenous populations and management models. In terms of methodology this requires reconstructing the poverty narrative of Uyghur peoples, including accounts of their exclusion, ejection from the original areas, and a special emphasis on autochthonous outlook on their environment and how Modernity invades their natural and human space.

Local and regional sociopolitical tensions have, in the final third of the twentieth century, forced or encouraged Uyghur emigration from XUAR and from the PRC, leading to the creation of distant exile communities. Through the inclusion of Uyghur studies (lacobs, 2016; Leibold, 2007; Millward, 2007, 2018; Sautman, 2000; Thum, 2012, among others), in a wider panorama of decolonial studies (Escobar, 2016; Restrepo, 2016; Santos y Meneses, 20I4, Ortega Santos y Olivieri, 2020, etc.), academia still faces the need to continue researching the socio-environmental impact of the modernization policies imposed by the PRC and its impact on the forms of autochthonous management of human and natural resources of the territory of XUAR. This, under Chinese domination in its different historical stages, has become a scenario of socioenvironmental conflicts: economic, political and identity consequences return the image of a colonized territory (Millward, 2007, 20 18; Sautman, 2000; Olivieri, 2020; Roberts, 2020), subjected to continuous extraction and repression processes by the central government. This institutional constraint, in recent years, has been legitimized by the PRC central state within the international community by accusing Uyghurs — culturally Muslims by majority - of terrorism, and thus including the whole oppression policies in the global scenario of GWOT (Roberts, 2020). This strategy hides the extractive-colonial interests that China has on the indigenous land of Uyghurs and other turkic peoples — such as Kazakhs, which represent more than a million people living in the territory-.

Post-coloniality and national independence in a global scenario have presented the overwhelming need to rethink Asia in all its political and cultural complexity, and to launch projects - such as the one proposed at the Bandung Conference (1955), in which China played a leading role - that promote a supra-national unity respectful of plurality (Peña, 1956; Yoon, 2018); however, it seems now necessary to analyze how Bandung narratives coexist with those of a sinocentric megaproject (Pérez, 20I4), with modernizing and developmental neo-colonial purposes (Islam, 20I9). The BRI proposes reestablishing connections between Europe, Asia and Africa — that is, reviving old geoschemes (Millward, 20I8) from a neo-colonial perspective (Clarke, 2017). Those links allegedly propose an economic supra-national development plan on an intercontinental scale, with the aim of modelling a scenario of revived cultural and human contacts, as well as commercial exchanges-. Nevertheless, the PRC's BRI underlies the imposition of its economic and cultural model and the application of measures of natural resources extraction on the affected regions. The current conflict in XUAR may be seen as socioenvironmental for: I.The economic divide between $\mathrm{Han} /$ yghur-North/south in the region, is also a divide between agrarian and commercial-urban economies; 2. The PRC development strategy is focused on urbanization, but within XUAR, the Uyghur south has been largely left out of urban-based development, or controlled by the predominantly Han organization of the Bingtuan (Production Construction Corps) which is now developing colonies in southern XUAR that largely excluded local Uyghurs from the benefits of housing and commercial opportunity; 3. XUAR has a systemic water deficit, and dire prospects within decades as climate change melts the glaciers on whose melt water the region currently relies.

Since the annexation of the territory of XUAR, the Government has been launching policies aimed at developing a greater control and power over the Uyghur historical region which represents a fundamental enclave both for natural resources extraction and for geopolitical strategies of Chinese politics and trade. The conquest and the subsequent mechanisms of coloniality have imposed in XUAR changes in the modes of management and those related to the natural environment, turning "particular ecosystems" into "modern forms of nature" (Escobar, 2016). Throughout this research, the term "coloniality" will be understood as a process that has certainly transformed the forms of domination deployed by Modernity, but not the structure of the center-periphery relations worldwide. In this particular case study, we are confronted with a scenario where decolonization has not happened; in fact, it is still denied, by the government itself, that there has been a colonization per se. Therefore, coloniality here is built from the creation of denialist and inclusionist discourses, which nullify the possibility of the subjects' -in broad terms: the land of XUAR and those who inhabit it - very existence. Since then, the ways of life of the subaltern groups, in all aspects, are subject to the Modern/Colonial model, it is necessary to re-dignify the community attempts of survival and resistance, as ones of subjects oppressed by the mechanisms of capitalist modernity.

Through this article I aim to reveal the Uyghurs perspective on how the official narratives about "development" and "modernity" proclaimed by the BRI, besides the monetary growth, hide colonial and oppressive control politics, and whose consequences are exclusion, repression, and even elimination of autochthonous identities in order to impose control over their territories and resources. So, jointly with a deep bibliographical and theoretical reflection, the very voices of exiled Uyghurs are here anonymously presented, based on Participatory Action Research (PAR) and Community Based Participatory Research (CBPR).

\section{KEYWORDS}

Xinjiang; Uyghurs; BRI; Bandung; Socio-Environmental Conflicts. 
Cuando Ferdinand von Richthofen, a finales del siglo XIX, utilizó por primera vez el término die Seidenstraßen - Rutas de la Seda - para definir el conjunto de conexiones que, ya desde la época Han (206 a.C.-220 d.C.), se establecieron entre China y el resto del mundo - conocido por Europa hasta el momento-, las consecuencias en el imaginario colectivo y el futuro establecimiento de narrativas que éste provocaría no podían preverse. Cierto es que la definición del geógrafo alemán adolece de una serie fundamental de matices: los flujos humanos, de bienes, materiales e ideas que se establecieron a través de lo que él denomina Seidenstraßen van mucho más allá de un simple comercio de seda por carretera. A través de estas conexiones, se propiciaba la creciente importancia del control sobre los recursos y el comercio de larga distancia, que incidió en la fundación de imperios a través de expediciones por desiertos y océanos (Frankopan, 20 18, p. 3); a la vez, poblaciones y culturas trascendían unas fronteras continentales que hoy en día tienen un peso harto más ingente que entonces.

El imaginario derivado de las Rutas de la Seda ha promovido la conformación de narrativas acerca de un pasado que se construye como una serie de períodos y regiones estancos, no devolviendo la imagen de un mundo interrelacionado e inclusivo — global, en suma - bien antes del advenimiento de la Modernidad — capitalista, colonial, eurocéntrica- Refleja, no obstante, un modelo clasificatorio eurocentrado, en su dimensión direccional oeste-este, que promueve la producción y difusión de mapas y estudios de notable precisión por parte de actores externos, cuyos intereses quedan fijados en fronteras determinadas y convencionales; las líneas fijadas en los mapas constituyen mucho más que simples marcadores cartográficos (Meneses, 2020, p. 5 I), construyéndose como "líneas abismales"| (Santos, 2007), operando una división entre el mundo “moderno" y el "de la tradición, primitivo": además de generar una periferialización de ese "otro lado de la línea", pues, crea lo que Boaventura de Sousa Santos describe como cartografía abismal (Meneses, 2020, p. 5I); los mapas se configuran por tanto como una herramienta fundacional de las narrativas de pertenencia/anexión identitaria, que a su vez forma parte de estrategias de control y sumisión; crean una imagen de unidad/homogeneidad, instrumental para mantener unas jerarquías de poder que no tienen en cuenta los regionalismos y particularismos históricos e identitarios propios de los diferentes territorios —un "universal”-; simultáneamente, infravaloran e invisibilizan las fundamentales conexiones y los continuos intercambios supra -e intra- regionales afro-eurasiáticos — como es el caso de las Rutas de la Seda—; una vez más, lo "universal" se convierte en un atributo del posesor, no del desposeído, y lo "universal" niega su propia particularidad atribuyéndose el "totum" de la "humanidad" (Henao Castro y Ernstson, 2019). Se fija, en suma, una separación ontológica — derivante de la convención geográfica- entre comunidades, partiendo de un discurso académico con evidentes consecuencias políticas y sociales; arrancan de un presupuesto erróneo que ha causado un conocimiento parcial e instrumental de un territorio,

\footnotetext{
“'Líneas radicales que dividen la realidad social en dos universos distintos: 'este lado de la línea' y 'el otro lado de la línea'. La división es tal que 'el otro lado de la línea' desaparece como realidad, se vuelve inexistente e incluso se produce como inexistente. La inexistencia significa no existir de ninguna manera relevante o comprensible. Todo lo que se produce como inexistente se excluye radicalmente porque permanece fuera del universo que la misma concepción de inclusión considera como el 'otro'. La característica fundamental del pensamiento abismal es la imposibilidad de la copresencia en ambos lados de la línea. El universo 'en este lado de la línea' sólo prevalece en la medida en que agota el campo de la realidad relevante: más allá de la línea solo hay inexistencia, invisibilidad y ausencia no dialéctica” (Santos, 2007, p. 7I). (Todas las traducciones presentes en este texto son mías). Este concepto, central en la propuesta epistemológica del sociólogo portugués Boaventura de Sousa Santos, constituye ya no sólo material académico fundamental para las especulaciones teóricas de académicas y académicos de todo el mundo (Santos, 2007), sino que, por iniciativa del propio ideador, se ha convertido en material artístico para una mayor y más profunda difusión de éste a nivel social y ciudadano.Acerca del pensamiento abismal, cfr. Santos, 2005, 2007, 20I 0a, 20I0b, 20I2, 20I4; Santos y Meneses, 20I4. Para analizar algunos de los productos artísticos/musicales, cfr.ALICE CES 20I6; Inquérito 2018.
} 
que en el caso de Asia que nos concierne, ocupa el 8,7\% del total de la superficie terrestre.

Asia ${ }^{2}$ es una entidad metageográfica con dimensiones territoriales, históricas, políticas, culturales, económicas, legales y estratégicas que han sido manipuladas creativamente con fines geopolíticos e ideológicos a lo largo de la historia (Millward, 2018). Si bien la denominación de "Asia" deriva de la antigüedad griega —en la obra de historiadores y geógrafos cuales Heródoto, Strabo, Plinio y Ptolomeo- ésta se empleaba refiriéndose de manera exclusiva a los territorios de Anatolia y el Imperio Persa. La cristiandad medieval, heredera de esta tradición clásica, establece una frontera de división imaginaria entre su idea de "yo" y el mundo "otro", oscuro, fantástico representado por Asia. Las civilizaciones que, al mismo tiempo, florecían en lo que hoy se define como Asia, mientras tanto, cartografiaban sus territorios sin que el término Asia apareciera en ninguna de sus fuentes. Sin —China—, Hind — India—, definían fronteras espaciales e imaginarias, indicando bien lugares reales, bien los límites del mundo conocido por los viajeros e intelectuales de la época. Asia se impone en el imaginario europeo como un lugar real que hay que conquistar, a la vez que un espacio fantástico y onírico. Estos conceptos no iban ligados a un espacio fijado e inmóvil, sino que se refieren a una geopolítica de la dominación, una hegemonía que se aplica a los ámbitos cultural y lingüístico, económico e institucional: “las comunidades campesinas, indígenas, han sobrevivido a los procesos de colonización y la violencia de los proyectos de los estados modernos, que buscan asimilarlas o incluso eliminarlas territorial, física, epistémicamente, cultural y lingüísticamente" (Meneses, 2020, p. 6I).

La inclusión histórica, bajo una única denominación, de las regiones que hoy conforman geopolíticamente Asia - cuyas fronteras se han establecido convencionalmente en los montes Urales y el río Ural en el oeste hasta el océano Pacífico al este, y en el océano Glaciar Ártico al norte hasta el Índico al sur, y engloban a cuarenta y nueve países oficialmente reconocidos por la Organización de Naciones Unidas (ONU)_, en épocas de postcolonialidad e independencias nacionales, ha presentado la necesidad contundente de repensar Asia en toda su complejidad política y cultural, y de poner en marcha proyectos — como el propuesto en la Conferencia de Bandung (1955) - que promuevan una unidad supranacional respetuosa de la pluralidad. Los geoesquemas (Millward, 2018) propuestos por la ONU, que distribuyen los diferentes estados-naciones asiáticos en regiones y subregiones con fines estadísticos, lejos de participar en la construcción de una visión plural y diversa, perpetúan una división estanca del territorio, asignándole a cada una de ellas unas características — religiosas, económicas, políticas etc.- homogeneizantes.

Restablecer vínculos de conexión entre Europa, Asia y África —esto es, reactivar antiguos geoesquemas desde una perspectiva neocolonial- es uno de los proyectos emprendidos en años recientes por la República Popular de China (RPCh), que publicita en apariencia un plan de desarrollo económico supranacional a escala intercontinental, con el objetivo de reavivar contactos e intercambios culturales, humanos y mercantiles. No obstante, subyace en este plan la imposición de su modelo económico y cultural en las regiones afectadas, sobre las que se ponen en marcha medidas de extractivismo de recursos naturales, con consecuencias subalternizantes por las identidades y poblaciones involucradas en el plan.A partir de 2013, con el anuncio por parte del actual presidente de la RPCh, Xi Jinping, acerca de la puesta en marcha de un enorme proyecto transna-

Esta definición de Asia se ha planteado inicialmente en una entrada para el Dicionário Alice (Olivieri, 2019). 
cional de revitalización de las antiguas rutas comerciales representadas por las Rutas de la Seda ${ }^{3}$, aumentadas en tamaño y alcance por rutas marítimas, y acompañadas por evidentes megaproyectos edilicios e infraestructurales, las medidas de desarrollo emprendidas en las últimas décadas en los territorios periféricos del país adquieren tintes desarrollistas aún más acentuados. Queda demostrando una vez más el creciente interés que estas regiones adquieren a nivel geoestratégico, y la necesidad de seguir perpetrando discursos de pertenencia e inclusión de un territorio, y consiguientes medidas de securización de éste con el fin de evitar todo tipo de sublevación y/o turbación de la "sociedad armoniosa" (Qarluq y McMillen, 20I I) publicitada por el estado.

"En 20I I, cuando Xi Jinping fue elegido, pensé... mucha, muchísima gente pensaba que las cosas inmediatamente mejorarían. La gente tenía esa esperanza, porque si miras a los artículos, decían que $\mathrm{Xi}$ Jinping visitó los Estados Unidos, es un tipo muy moderno, y quizás llevaría a China hacia un nuevo camino. Pero ahora, de verdad que la está llevando hacia un nuevo camino, se está convirtiendo en un estado totalitario, draconiano" (entrevistado I, comunicación personal confidencial a la autora).

El objetivo de este artículo es el de investigar el impacto de la Belt and Road Initiative (BRI) en la apropiación de materiales y energía en la Región Autónoma Uigur ${ }^{4}$ de Xinjiang ${ }^{5}$ (XUAR) de la RPCh, cómo ésta bebe de las narrativas históricas construidas en torno a las Rutas de la Seda, y cómo se ha pasado de la firma, hace poco más de medio siglo, de un pacto afroasiático de cooperación entre naciones y la firme condena a toda forma de colonialismo, a promover un megaproyecto que yergue a la RPCh cual nuevo actor colonial a nivel mundial. Para ello, se ha decidido dividir el texto en cuatro apartados: en la introducción, se está analizando brevemente cómo las narrativas han sido empleadas, por distintos gobiernos y en épocas diversas, para propiciar un conocimiento geoesquemático del territorio asiático, y cómo esto ha provocado la invisibilización de las heterogeneidades propias de un espacio tan amplio como lo es el continente en cuestión. Posteriormente, se analizarán los planes de desarrollo y modernización propuestos por la $\mathrm{BRI}$, sugiriendo sus consecuencias ambientales y sociales. En el siguiente apartado, se incidirá en un análisis del pacto afroasiático firmado en Bandung en 1955, en materia de autodeterminación, extractivismo y condena del colonialismo, y se realizará un análisis comparado con el texto oficial de la Ley de Autonomía Regional de la RPCh y su aplicación práctica en XUAR dentro del proyecto de la BRI, hilando estos temas mediante relatos de historia oral de personas uigures en la diáspora. Finalmente, en el capítulo conclusivo, se discurrirá acerca de los grandes ámbitos que han guiado el entramado de este artículo con herramientas de ecología política, y se tratará de

3 También conocida como One Belt One Road Initiative (OBOR), The Belt \& Road (B\&R), Yi dai yi lu en chino. Aquí se utilizará la abreviación BRI - Belt and Road Initiative- La denominación en español "Iniciativa del Cinturón y Ruta de la Seda" se sustituye en ocasiones con la abreviatura NRS (Nueva Ruta de la Seda), para atestiguar su voluntad de continuidad con las Rutas de la Seda antiguas/tradicionales.

4 Oficialmente, según la Constitución de China, la Zhonghua minzu — pueblo chino- se compone por 56 nacionalidades, de las que la han ocupa alrededor del 91-92\% de la población total del país. La nacionalidad uigur, a la que se hará constante referencia en este artículo representa, por población, la décima a escala nacional, y la segunda de las minorías nacionales de fe musulmana.

5 Desde el principio, consideramos necesaria una precisión terminológica: nos referiremos a la Región Autónoma Uigur de Xinjiang con la abreviación XUAR - Xinjiang Uyghur Autonomous Region - cuando hablemos del territorio geopolítico tal y como lo establece y conforma la República Popular de China (RPCh): haremos referencia a XUAR cuando nombremos cuestiones relacionadas con las políticas impuestas por el Estado Central sobre ese territorio -esto es, cuando detallemos situaciones que implican una relación entre la región y la RPCh-. Elegimos utilizar una abreviación, en vez de usar el término Xinjiang, para remarcar y hacer patente la oficial —y no real— "autonomía" de la región, así como el reconocimiento de su "pertenencia" al pueblo uigur. 
demostrar cómo la BRI es la viva representación del plan neocolonial de la RPCh, pese a la propaganda armonizante difundida por el Partido Comunista Chino (PCCh), y su impacto en la (in) justicia socioambiental en el país.

El reto de las ciencias sociales y las humanidades es el de localizar y particularizar los conocimientos, multiplicar los autores ensalzando los saberes desde las diferentes Asias y no sobre ellas, y promoviendo un proyecto no geoesquemático y no competitivo con otros actores, sino de diálogo constante y horizontal entre ellos. En apoyo de este imaginario, es necesario crear espacios académicos e intelectuales que enfrenten la cuestión uigur. Esto requiere crear nuevas formas de comprensión social desde perspectivas no eurocéntricas y, en este caso, no sinocéntricas, así como nuevas estrategias para crear conocimiento que vayan más allá de los legados coloniales y nortocéntricos de las ciencias sociales actuales. También requiere profundizar en formas pluralistas de pensamiento social constructivo que están surgiendo en diferentes lugares del "sur", incluida la región uigur. Habitar el sur no es simplemente ponerse del lado de los que vienen de una región geográfica determinada. Es ponerse metafóricamente del lado de aquellas gentes que sufren los daños causados por el capitalismo y el colonialismo a escala nacional y global.

\section{I. "And boss became to us"}

La región de XUAR representa un vasto territorio — de alrededor de I,66 millones de $\mathrm{km}^{2}$, una sexta parte de la superficie total del país - , situado en el extremo noroccidental de la RPCh, y con más de $5.600 \mathrm{~km}$ de fronteras compartidas con otras repúblicas de Asia Central: Mongolia, Rusia, Kazajistán, Kirguistán, Tayikistán, Afganistán, Pakistán e India. La conformación topográfica de la región nos devuelve la imagen de un territorio preponderantemente montañoso y caracterizado por depresiones áridas y desiertos, lo que explica la relativa escasez poblacional que se registra — cerca de - diecisiete millones de habitantes (Bellér $\square$ Hann, 1997, p. 88). Históricamente perteneciente a poblaciones túrquicas (Golden, 2006) indígenas —nómadas y seminómadas-, fue anexionado a las fronteras chinas durante la época Qing (1644-1912) en 1759; tras el establecimiento de una colonia militar en la zona, las poblaciones autóctonas lograron en varias ocasiones recuperar su gobierno independiente, aunque la superioridad militar china consiguió realizar su sometimiento formal en 1884, asignándole el topónimo de Xinjiang — Nueva Frontera, en chino-. Durante más de un siglo se estableció una colonia militar en el territorio, cual método imperial para mantener el control sobre éste, lo que generó más de cuarenta intentos de rebelión por parte de las poblaciones indígenas; de éstos, la revuelta de 1864 tuvo éxito, permitiendo el establecimiento del territorio independiente de Yetteshahar, aunque años de conflicto armado contra las tropas manchúes provocaron su capitulación y su anexión formal bajo el topónimo de Xinjiang en I884 (Clarke, 2007, p. 26I). Esto ocurrió en un momento histórico en el que la dinastía Qing, próxima a su fin, estaba cambiando su estructura de dominación: por un lado, estaba adoptando las características de un estado moderno y, por otro, estaba trasladando el poder burocrático en manos de un cada vez más importante grupo étnico han, eliminando los sistemas de gobierno locales (Bäg) para convertirlos en una red burocrática gestionada mayoritariamente por élites han (Roberts, 2020, p. 30). Subrayar estos factores es clave para entender de forma más contextualizada la situación actual del territorio uigur y sus gentes en relación con la nacionalidad mayoritaria y el gobierno del PCCh. 
Las políticas aplicadas por China —en sus diferentes etapas, dinástica y republicanas, nacionalista y comunista: control territorial, diplomacia superior, concesiones mínimas y ficticias para mantener el orden, extractivismo programático — son el manifiesto de lo que, para otras potencias expansionistas, no dudaríamos en llamar “colonialismo": la literatura más comprometida con los estudios uigures, en los últimos años, no duda en aplicar este término a las relaciones establecidas desde la época Qing en los territorios periféricos y recién anexionados del imperio6; esto requiere reconocer las características propias del colonialismo chino y evitar la universalización del colonialismo europeo como se practicó en los siglos XVII y XVIII como "el único colonialismo posible":"los uigures pensamos que estamos bajo ocupación y colonización chinas, y que Turkestán Oriental no es parte de China” (entrevistado 3, comunicación personal confidencial a la autora). Las justificaciones de desarrollo, modernización y pacificación encajan perfectamente en la definición de extractivismo de Ramón Grosfoguel (2008): una forma de fascismo flagrante que se manifiesta a través de políticas que van desde el "cristianízate o te mato del siglo XVI, al civilízate o te mato del siglo $X I X$, al desarróllate o te mato del siglo $X X$, al más reciente neoliberalízate o te mato de finales del siglo XX y el democratízate o te mato de inicios del siglo XXl". Aunque a China oficialmente le ha faltado la fase evangelizadora, en nuestros términos eurocentrados, las otras se reconstruyen fácilmente. Incluso la fase "democrática", que podría parecer la más lejana a la actual conformación del Estado chino, está representada, en los corpi legislativos, por expresiones cuales "dictadura democrática del pueblo", “democracia socialista” y el objetivo de "transformar la madre patria en un país socialista que sea próspero, democrático y culturalmente avanzado" (Regional Ethnic Autonomy Law of the People's Republic of China, 1984, Preamble).

Es importante diferenciar entre dos conceptos que están a la base del marco epistemológico que se usa en este artículo, siguiendo la definición que de ellos subraya Nelson MaldonadoTorres (Castro-Gómez y Grosfoguel, 2007, p. I 3 I):

"colonialismo denota una relación política y económica en la cual la soberanía de un pueblo reside en el poder de otro pueblo o nación, lo que constituye a tal nación en un imperio. Distinto a esta idea, la colonialidad se refiere a un patrón de poder que emergió como resultado del colonialismo moderno, pero que en vez de estar limitado a una relación formal de poder entre dos pueblos o naciones, más bien se refiere a la forma como el trabajo, el conocimiento, la autoridad y las relaciones intersubjetivas se articulan entre sí a través del mercado capitalista mundial y de la idea de raza"7.

A lo largo de este estudio, el término "colonialidad" se entenderá por tanto como un "proceso que ciertamente ha transformado las formas de dominación desplegadas por la Modernidad, pero no la estructura de las relaciones centro-periferia a escala mundial" (Castro-Gómez y Grosfoguel, 2007, p. I3). Desde nuestra perspectiva, nos situamos en un escenario en el que la descolonización no ha acontecido; de hecho, en el que se sigue negando, desde el propio gobierno, que haya existido una colonización per se. La colonialidad, pues, aquí, se construye desde la propia creación de discursos negacionistas e inclusionistas, que anulan la posibilidad de la misma existen-

\footnotetext{
Cfr.Anand, 2019; Millward, 2021; Oidtmann, 2018; Roberts, 2020

Los resaltados no están presentes en el texto original.
} 
cia del sujeto —en términos amplios: la tierra del actual XUAR y quienes la habitan—en cuestión.

Partiendo de las conclusiones de Jason Moore (2015, pp. 191-192), nos situamos en un doble escenario: por un lado, en la construcción de una naturaleza "externa", un espacio "plano y geométrico", y un tiempo "lineal”; por otro, en una nueva configuración de la explotación y la apropiación, al servicio de la mercantilización —esto es, de las bases del capitalismo-. Según el autor, pues, el capitalismo, para subsistir, debe mercantilizar la vida y el trabajo, y sin embargo depende precisamente de la vida y el trabajo no mercantilizados para ello. En XUAR, al igual que en otros ejemplos proporcionado por los autores, la fuerza bruta -léase, en nuestro caso, la ocupación militar - no ha sido siempre suficiente —además de representar un coste - para poder mantener el control sobre el territorio y los recursos necesarios para la acumulación de capital.

El concepto de colonialidad territorial, aquí, por lo tanto, hace referencia no sólo a medidas prácticas de extracción de recursos, sino también a la instilación de narrativas desarrollistas — "nuevas formas de mapear, categorizar y vigilar" (Moore, 20I5, p. 192) - que poseen unas aplicaciones reales e impuestas en el territorio. La misma noción/discurso sobre el subdesarrollo de la región y, por ende, la necesidad de una intervención "superior/Moderna" para suplir a las faltas primitivas de los modelos de gestión indígena comunitaria, han de pasar por un prisma de crítica a la monetarización y capitalización coloniales.

Estos extractivismos, tal y como los define Eduardo Gudynas (2016) se entienden "como la apropiación de recursos naturales en grandes volúmenes o bajo prácticas de alta intensidad, para nutrir masivas exportaciones hacia la globalización. Los ejemplos más conocidos son [...] las perforaciones petroleras o las inmensidades de los monocultivos" (p. I3), que aplican perfectamente al caso que nos corresponde. Si "la raza fue el factor más importante en [...] el resultado de las políticas de uso de la tierra locales, estatales y federales" (Vergès, 2017, p. 72), las políticas represivas aplicadas por la RPCh a las poblaciones túrquicas autóctonas de XUAR entran de derecho en el patrón global de racismo ambiental propugnado por Vergès (2017, p. 73).

Nos situamos en el marco de la definición de Antropoceno proporcionada por John McNeill (2019): una era o época en la historia de la Tierra en la que los seres humanos han ejercido una influencia dominante sobre el medio ambiente global $y$, de alguna forma, han moldeado los ciclos biogeoquímicos fundamentales que operan en ella, creando una suerte de "segunda naturaleza" por encima de, y en algunos casos reemplazando a la naturaleza original. No obstante, parece importante subrayar el fuerte carácter politizante de las relacionalidades - colonialismo y capitalismo- que aquí se analizan, por lo que es preciso traer a colación la reflexión de Swyngedouw y Ernstson acerca de la mise-en-scène de unas narrativas - Antropo-escenas - que, pese a su completa falta de homogeneidad, consiguen relegar en una posición subalterna — fuera de la escena, Antropo-obscena - a ciertas voces y formas de actuaciones (2018, p. 4).

La idea misma de las Rutas de la Seda, pues, es un producto de tiempos de imperialismo e industrialización (Millward, 20I8). La inclusión de las tierras que tradicionalmente han constituido los enclaves de las antiguas Seidenstraßen dentro de la cartografía china conlleva necesariamente su patrimonialización $-\mathrm{y}$ la de sus recursos naturales, identitarios y humanos- $-y$, por ende, su vigilancia y control. 


\section{Figura I. Localización de XUAR y su importancia geoestratégica en la BRI}

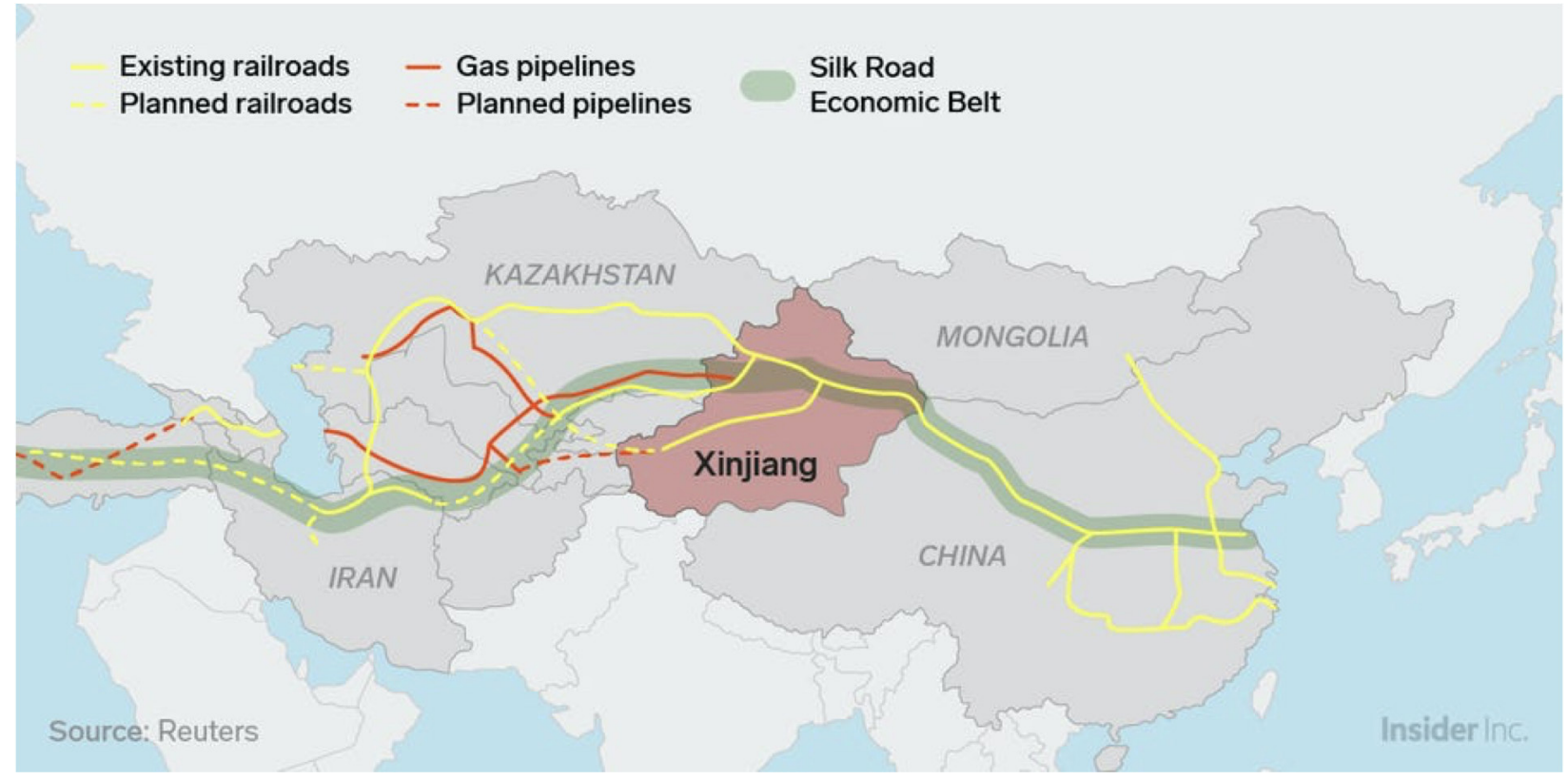

Fuente: Business insider (23.02.2019). This map shows a trillion-dollar reason why china is oppressing more than a million muslims. Recuperado de: https://www.businessinsider.com/map-explains-china-crackdown-on-uighur-muslims-in-xinjiang-20 I 9-2?IR=T ( I I.08.2020)

Respecto de la colonialidad del poder territorial, que Walter Mignolo (2000) define como el campo de la intersubjetividad en el que cierto grupo de personas define lo que es territorialmente correcto $y$, por lo tanto, construye un cuerpo de narrativas legitimadoras, esto se ejerce tanto en los escenarios territoriales globales como en los locales. En el caso de China, las políticas agrícolas, industriales y ambientales aplicadas ya en la época de Mao promovieron una antropización de la naturaleza, rompiendo formas de manejo anteriores y autóctonas —la mercantilización de la naturaleza que se ha mencionado anteriormente- - El megaproyecto representado por la BRI coloca a $\mathrm{Xi}$ - y a la RPCh - en una posición hegemónica en la imposición de la lógica capitalista en los intercambios de materiales y energías, en el marco de lo que Crosby definió imperialismo ecológico (1988).

El poder ejercido en la RPCh — que emana desde Beijing hacia las zonas periféricastiende a lograr una homogeneización de la diversidad político-étnica al servicio de un proyecto estatal/imperial que pesa en el entorno y de éste se apropia.A nivel global, opera como transmisor de procesos de explotación de recursos naturales y ejecutor de proyectos capitalistas; a nivel local, visibiliza la conexión, construida desde la hegemonía, de una naturaleza "barata" —entendida como capital constante- y la organización global de una fuerza-trabajo, además de "barata", racializada y disponible —a la vez que desechable- (Vergès, 20I7, p. 73).

Las narrativas beben y amplifican las historias construidas alrededor de las carreteras terrestres, legendarios corredores comerciales centroasiáticos operativos ya desde la China han, y marítimas, que navegan en las rutas abiertas por Zheng He (Millward, 20 I8); la creación de nuevos caminos, que conectan a cerca de setenta países y sus respectivas economías — pese a que aún 
no exista una lista oficial definitiva de naciones participantes - (The World Bank, 20I8, párr. 5-7), bajo el estandarte de la cooperación intranacional y la armonía promovido por la BRI nos autoriza a mirarla como un "geoesquema" más: "una entidad conceptual metageográfica de escala regional con dimensiones territoriales, históricas, políticas, culturales, económicas, legales y estratégicas, susceptibles de manipulación creativa con fines geopolíticos e ideológicos" (Millward, 2018).

Figura 2. Principales corredores comerciales desde y hacia China y algunas de las infraestructuras y puertos más importantes construidos o planificados con la inversión china en el BRI

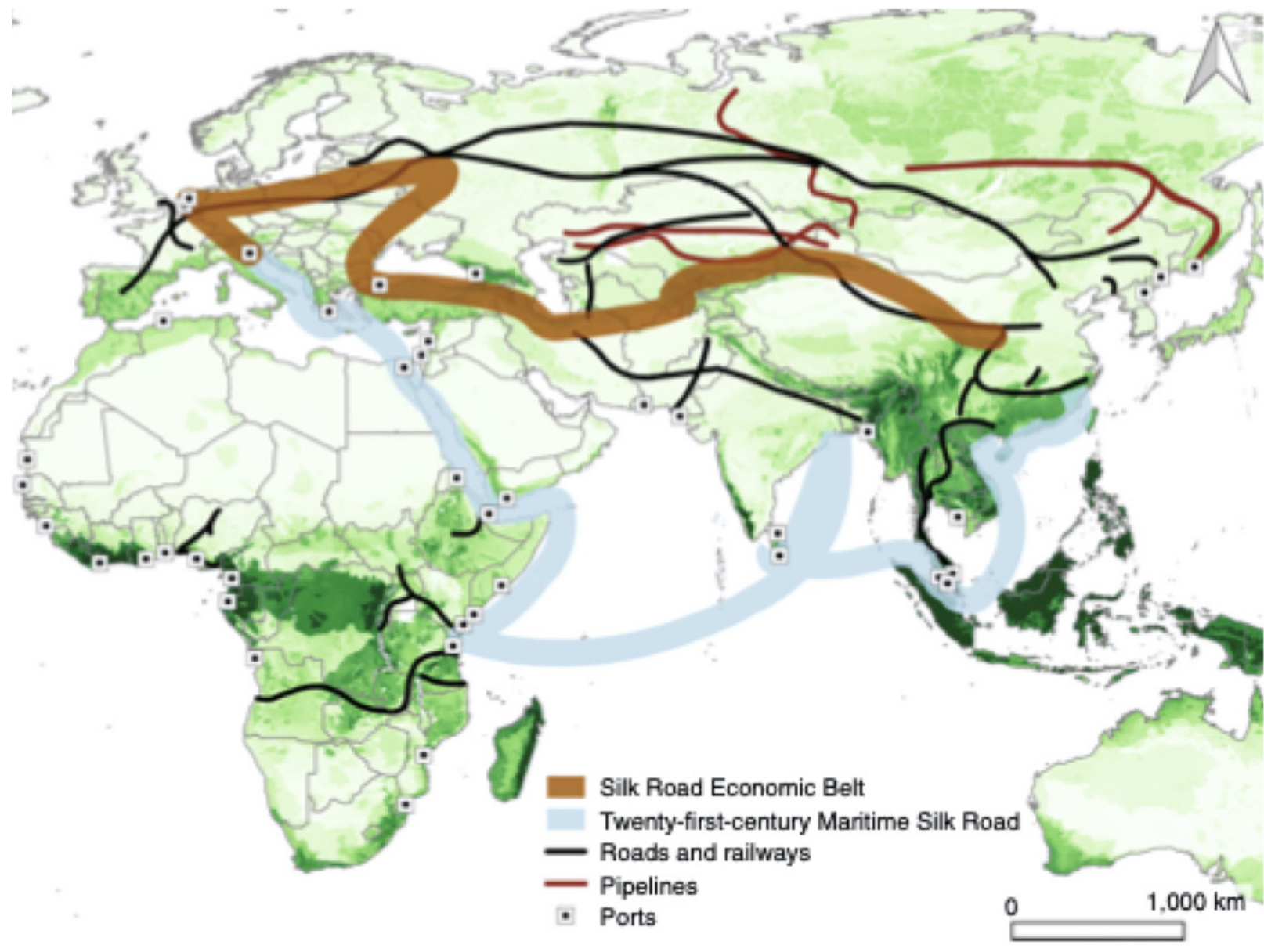

Fuente:Ascensão et al., 20 I8, p. 207.

Como se deduce de la Figura 2, los proyectos centrales para conectar la RPCh con otras regiones incluyen: oleoductos y gasoductos a Rusia, Kazajistán y Myanmar; una red ferroviaria a los Países Bajos; y un ferrocarril de alta velocidad a Singapur. Otras mega infraestructuras, que apuntan a conectar regiones fuera de China, incluyen: la carretera que une Peshawar y Karachi en Pakistán; el ferrocarril recientemente inaugurado entre Nairobi y Mombasa; y el primer ferrocarril totalmente electrificado que une Addis Abeba con Djibouti (Ascensão et al., 20 I8, p. 206). Los objetivos declarados de la $\mathrm{BRI}$ son los de promover la cooperación pacífica y el desarrollo común en todo el mundo ${ }^{8}$, fin en el que todos los países son animados a participar en pie de igualdad. Se

8 La propaganda "clásica" —la de los carteles propagandísticos de la Gran Revolución Cultural Proletaria — se ha adaptado a los tiempos de 
define como el medio para un nuevo sistema de gobernanza económica global, promoviendo un flujo eficiente de materiales y una integración profunda de los mercados, para lograr un desarrollo diversificado, independiente, equilibrado y sostenible.

Fuentes oficiales chinas también subrayan que, de concretarse la visión de la BRI, se crearía un corredor económico prometedor, que beneficiaría directamente a una población de 4.400 millones de personas - cerca del 63\% de la población mundial-, con un PIB anual colectivo de 2,I billones de dólares - $29 \%$ de la riqueza mundial- Aproximadamente un año tras su anuncio oficial, Xi reveló en Beijing, durante las reuniones de Cooperación Económica Asia-Pacífico (APEC) en noviembre de 20I4, que la RPCh establecería un fondo de 40.000 millones de dólares para financiar la construcción de la BRI, mientras el Banco de China publicó sus planes para extender créditos superiores a los 20.000 millones de dólares para proyectos relacionados con la $\mathrm{BRI}$ en 2015, y 100.000 millones de dólares más durante los tres años siguientes (Johnson, 20I6, p. I).

A pesar de estos objetivos loables, las aspiraciones de desarrollo económico bajo la BRI pueden chocar con los objetivos de la sostenibilidad ambiental, por promover activamente la expansión y actualización de infraestructuras de transporte en áreas ambientalmente sensibles y las grandes cantidades de materia prima necesarias para respaldar esa expansión. Como bien apunta James Millward (2018), la construcción de ferrocarriles, con capital financiero y por constructoras europeas, fue históricamente considerada como uno de los actos más invasivos de la injerencia colonial europea en el territorio. Hoy en día, la RPCh ofrece préstamos y financiaciones para que otros países afroasiáticos desarrollen sus infraestructuras para facilitar sus exportaciones y los intercambios comerciales con ellas. “Acaso hay diferencia?”, habría preguntado Benedict Anderson $(20 \mathrm{II})$. 


\section{2. "Colonialism in all its manifestations is an evil"}

Figura 3. Mapa de los participantes en la conferencia de Bandung

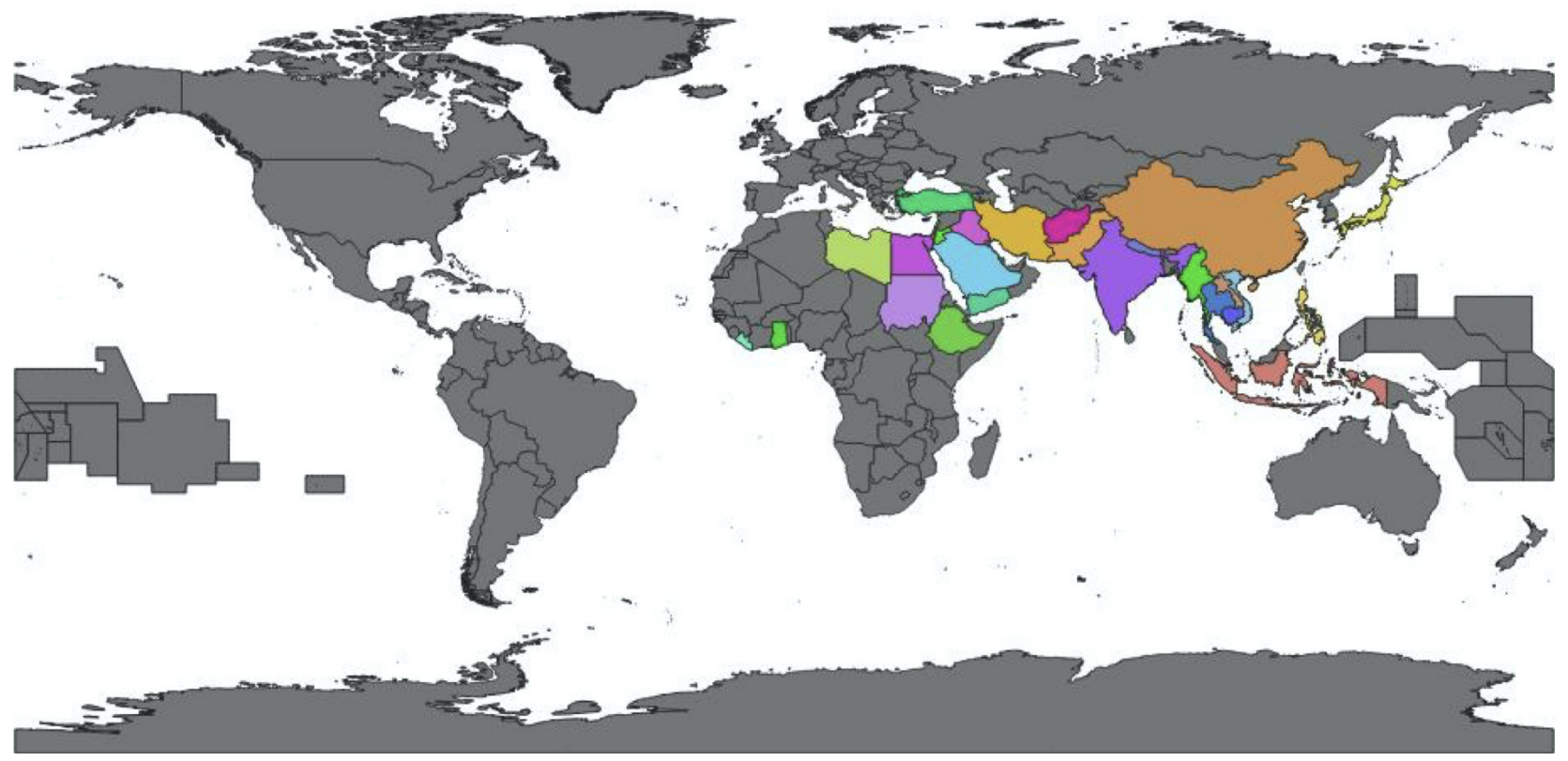

Fuente: Elaboración propia

"La Conferencia está de acuerdo en declarar que el colonialismo en todas sus manifestaciones es un mal, al que debe ponerse fin rápidamente" (Asia-Africa speak from Bandung, 1955, p. 165). Firmaba en Bandung Zhou Enlai, en representación de la RPCh, el punto D. I a. del Comunicado Final de la Conferencia Afroasiática, consensuado entre los veintinueve países participantes (Figura 3), en abril de 1955.

No obstante, retomando la definición que proporciona Maldonado-Torres ${ }^{9}$ (Castro-Gómez y Grosfoguel, 2007, p. I3I) y que citamos arriba y si, más generalmente, nos referimos con "colonialismo" a una práctica antigua de conquista, usurpación y subalternización, sin caer en "la que el historiador del imperialismo Bernard Porter llama la 'falacia del agua salada', la idea de que la conquista solo se convierte en imperialismo cuando cruza agua salada" (Chomsky, 2016, p. 52), la historia de XUAR es, de forma definitiva tras 1949, una historia colonial -lo que convierte a la RPCh en una potencia colonial-, si se analiza bajo los ejes propuestos por Steinmetz (20I4): (I) capitalismo; (2) geopolíticas, guerra y violencia; (3) representación cultural y subjetividad; (4) resistencia y colaboración de los actores colonizados; (5) dimensión institucional de los imperios y las colonias; y (6) conflicto y compromiso entre colonizadores en el núcleo de los estados coloniales ${ }^{10}$.

9 “Colonialismo denota una relación política y económica en la cual la soberanía de un pueblo reside en el poder de otro pueblo o nación, lo que constituye a tal nación en un imperio".

10 A este propósito, es fundamental conocer el trabajo de grupos de investigadores e investigadoras con un fuerte compromiso social hacia el pueblo uigur, que trabajan en desvelar, a través no sólo de sus productos académicos, sino más abiertamente en las Redes Sociales, los mecanismos e represión perpetrados por el gobierno de la RPCh sobre el pueblo uigur. Los puntos aquí recogidos por Steinmetz se visibilizan en la propaganda del PCCh contra la identidad uigur, denunciada, entre otros, por Timothy Grose en su cuenta de Twitter (Grose, 2020). 
La justificación que el estado proporciona, históricamente, para librarse de estas acusaciones deriva de una aberración historiográfica: China siempre ha sido lo que hoy en día se llama China; un actor cultural-político único, unitario y que, aun cuando estuvo gobernado por un "emperador", nunca fue "imperialista", construyendo unas narrativas que erigen a China, con este nombre y forma, como existente incluso antes de que los Qing, en el siglo XVIII, conquistasen algunos de los territorios que la constituyen. Se crea la imagen, por lo tanto, de unas "nacionalidades minoritarias" o "etnias" — que hoy en día son- chinas, como "históricamente chinas", aun antes de que ellas y sus tierras cayeran bajo el dominio de un Estado “chino": "La República Popular de China es un estado unitario multinacional creado conjuntamente por los pueblos de todas sus nacionalidades étnicas" (Regional Ethnic Autonomy Law of the People's Republic of China, 1984, Preamble).

Los veintinueve representantes de los países que se reunieron en Bandung firmaron, unánimemente, una “declaración para la promoción de la paz y cooperación mundiales” en diez puntos, que incluían la carta estatutaria de las Naciones Unidas y los Cinco Principios del Primer Ministro de la India: respeto mutuo, integridad y soberanía territorial, no agresión y no interferencia en los asuntos internos, equidad y beneficio mutuo, coexistencia pacífica. Efectivamente, estos principios se reflejan en la redacción de la Ley de Autonomía Étnica Regional de la RPCh, de 1984, en cuyo preámbulo se expresa:

"La autonomía étnica regional significa que las minorías étnicas, bajo un liderazgo estatal unificado, practican la autonomía regional en las áreas donde viven en comunidades concentradas y establecen agencias autónomas para el ejercicio del poder de autonomía. La autonomía étnica regional refleja el pleno respeto y garantía del Estado por el derecho de las minorías étnicas a administrar sus asuntos internos y su adhesión al principio de igualdad, unidad y prosperidad común para todas las nacionalidades.

La autonomía étnica regional ha jugado un papel enorme al dar pleno valor al entusiasmo de las minorías étnicas por ser dueñas de sus propios asuntos, al desarrollar entre ellas una relación socialista de igualdad, unidad y asistencia mutua, consolidar la unificación del país y promover construcción socialista en las áreas étnicas autónomas y el resto del país. Continuar fortaleciendo y mejorando el sistema regional de autonomía étnica le permitirá desempeñar un papel aún mayor en la modernización socialista del país en los años venideros" (Regional Ethnic Autonomy Law of the People's Republic of China, I 984, Preamble) ${ }^{\prime \prime}$.

Se han enfatizado, en la cita, conceptos que parece fundamental aquí remarcar: el gobierno de la RPCh expresa en su cuerpo de ley la intención de acatar y practicar los principios funda-

"Los resaltados no están presentes en el texto original. 
mentales firmados en Bandung, promoviendo una imagen de "prosperidad común", "igualdad" y "unidad", logradas a través del "respeto" de la "autodeterminación" de los pueblos minoritarios.

"Oficialmente reconocen que la tierra pertenece al pueblo uigur. Región "autónoma" uigur. En la realidad, nunca han concedido ninguna autonomía, pero en las escrituras, en la ley, legalmente, reconocen que esta tierra les pertenece a los uigures. Desde Mao, Mao Zedong, en los cincuenta... En ese momento, China no era poderosa, era un país débil, necesitaba apoyo, no tanto internacional, sino sobre todo soviético. Además, los comunistas necesitaban el apoyo de las gentes locales, como uigures, mongoles, gentes de las minorías. Por eso China le reconoce la "autonomía" de la región. ... [La ley de autonomía regional] es perfecta.Tú la lees y dices "oh, esto está bien"; pero en la realidad, no existe nada de autonomía, por supuesto. No puedes discutir ninguna cuestión autonómica, o sea, sólo puedes decir "sí, la ley está bien", pero si das alguna opinión... si muestras algo de criticismo, en cualquier momento quizás te conviertas en un/a terrorista, o cosas así, quién sabe, o un/a separatista" (entrevistado 2, comunicación personal confidencial a la autora).

No obstante, todo eso subyace a los espejismos de la Modernidad capitalista implantada en el territorio; una Modernidad cuya comprensión "descansa en varios supuestos que controlan el grado de comprensión del mundo que esta teoría puede lograr, al mismo tiempo que legitima una realidad histórica específica constituida sobre la base de la jerarquización, la explotación y el despojo" (Suárez-Krabbe, 2019, párr. 2).

Philippe Le Billon define un conflicto ambiental de la siguiente forma: "Un conflicto ambiental puede entenderse ampliamente como un conflicto social relacionado con el medio ambiente [...] Desde una perspectiva neomalthusiana, los conflictos ambientales también consisten en conflictos resultantes de procesos ambientales, especialmente la escasez de recursos que supuestamente ejerce presión sobre las relaciones sociales, incluso si el conflicto per se no se trata de esos recursos ambientales "escasos" [...] Una variante de este argumento impulsado por la escasez es la llamada "maldición de los recursos", según la cual la explotación de recursos abundantes en contextos económicos no diversificados resulta en altos niveles de grandes ingresos y dependencia de recursos, que aumentaría la vulnerabilidad a los conflictos pues socava la calidad de las instituciones, expone a las sociedades a conmociones económicas y exacerba las tensiones sobre la distribución de las rentas de los recursos y, en general, los costos y beneficios de los sectores de recursos dominantes" (Le Billon, 20I5, pp. 599-600). 
La situación que se vive actualmente en XUAR puede considerarse un conflicto socioambiental por las siguientes razones: (I) La división económica entre las poblaciones china han y uigur, en el norte y el sur de la región, es asimismo una división entre economías comerciales urbanas y agrarias; (2) la estrategia de desarrollo de la RPCh se centra en la urbanización; no obstante, dentro de la región de XUAR, el sur, mayoritariamente poblado por uigures, se ha dejado en gran medida al margen del desarrollo urbano, promovido en cambio en el norte; en las zonas urbanizadas en el sur, este proceso está controlado por organizaciones predominantemente han: los Bingtuan ${ }^{12}$ (Cuerpos de Construcción de Producción), en cuyas colonias la población uigur es excluida de los beneficios comerciales e industriales. (3) XUAR es una región con un déficit sistémico de agua y perspectivas nefastas en las próximas décadas a medida que el cambio climático derrite los glaciares de cuya agua de deshielo depende actualmente la región (Olivieri y Ortega Santos, 2020). Este es un factor que el actual programa de desarrollo de XUAR y la BRI ignoran sistemáticamente, promoviendo el desarrollo de parques industriales sin importar los costos ambientales y las necesidades de recursos.

Conforme los lazos de solidaridad Asia-África promovidos por Bandung fueron resquebrajándose bajo el peso de las crecientes fricciones entre los propios países participantes, y la RPCh fue adquiriendo un papel cada vez más relevante en la geopolítica mundial, en una era de globalización en la que la inversión exterior de la RPCh en los países vecinos se está expandiendo rápidamente (Summers, 2016, p. I.63I), la importancia geoestratégica de XUAR y la necesidad de mantener el control sobre ella han visibilizado la falta de aplicación de los corpi legales por los propios organismos gubernamentales; la necesidad de "capacitar a un gran número de minorías para que se conviertan en cuadros en todos los niveles, así como en personal especializado y trabajadores calificados de todas las profesiones y oficios" (Regional Ethnic Autonomy Law of the People's Republic of China, 1984, Preamble), que hoy en día se materializa en XUAR mediante la detención de millones de personas túrquicas ${ }^{13}$ en campos de concentración gestionados por el estado, prima sobre el principio por el cual "se prohíbe la discriminación y la opresión de cualquier nacionalidad” (Regional Ethnic Autonomy Law of the People’s Republic of China, 1984, I.9).

Si comparamos las Figuras 2 y 3, resulta evidente la participación de muchas de las naciones de la Conferencia Afroasiática en el nuevo escenario mundial planteado por la RPCh: los principios de cooperación promovidos en Bandung, y recuperados en el cincuenta aniversario de la celebración de la Conferencia con la redacción del NAASP (New Asian-African Strategic Partnership), para reincidir en la necesidad de promover la colaboración política, económica y cultural entre los dos continentes se materializan, pocos años más tarde, en la BRI. Para construir la conectividad y cooperación planteadas, a través de seis principales corredores económicos que abarcan China y: Mongolia y Rusia; Países euroasiáticos;Asia central y occidental; Pakistán; otros países del subcontinente indio; e Indochina, Asia necesita veintiséis billones de dólares para inversiones en infraestructura hasta 2030, y la RPCh se propone como actor indispensable para proporcionar parte de esto. Sus inversiones, al construir infraestructura, se presentan como impactos positivos en los países involucrados. Publicitar el beneficio mutuo es una estrategia que, a la vez, ayudará a

\footnotetext{
12 Xinjiang shengchan jianshe bingtuan - 新疆生产建设兵团, son una colonia militar-agrícola fundada en 1954 con la responsabilidad de “desarrollar eriales y defender la frontera”. Para profundizar más en el papel de estos Cuerpos de Producción, cfr. Cliff, 2009.

13 El Informe sobre las actividades de la RPCh en XUAR redactado por Campaign for Uyghurs proporciona datos impactantes acerca de los números de personas detenidas y mecanismos de "formación". Cfr. Campaign For Uyghurs, 2020.
} 
desarrollar mercados para los productos de China a largo plazo y a aliviar el exceso de capacidad industrial a corto plazo. El BRI prioriza a la infraestructura y la financiación primero (OECD, 20I8).

En XUAR, tradicionalmente cuna de las míticas Seidenstraßen, hoy punto de emanación de muchas de las ramificaciones materiales de la BRI (Figura I), la construcción de estas infraestructuras esenciales para la Iniciativa, constituye la materialización del Artículo 1.6 de la Ley de Autonomía Étnica Regional (1984): “Las agencias autónomas en áreas étnicas autónomas lideran a las personas de las diversas nacionalidades en un esfuerzo concentrado para promover la modernización socialista". Los planes de la BRI muestran que el objetivo regional es el de hacer un buen uso de la ventaja geográfica de XUAR cual ventana hacia el oeste, para profundizar la comunicación y la cooperación con los países de Asia Central, Meridional y Occidental, convertirlo en un enclave en las redes de transportes, y un centro de comercio, logístico, cultural, científico y educativo, así como fomentar su papel central en el cinturón económico de las nuevas Rutas de la Seda (Summers, 2016, p. I.633). De hecho, como afirma Millward (2009), el territorio que hoy se denomina XUAR siempre ha sido importante por su posición intermedia.

Lejos de disminuir su importancia cultural y geopolítica de esta "intermediación" a medida que la región se ha integrado más estrechamente con China, ésta ha, por lo contrario, simultáneamente ido acercándose al mundo. No obstante, y pese a que la globalización debería intrínsecamente traer consigo todo tipo de posibilidades para significar y dignificar la importancia de las identidades regionales y locales — por romper, en teoría, el control que los estados nacionales tienen sobre el crecimiento económico y los imaginarios políticos- (Agnew, 2010, p. 579), mantener el control sobre una región histórica, étnica y culturalmente ajena a la "china", y que sigue reivindicando su independencia nacional frente a los abusos coloniales de Beijing representa para el PCCh una prioridad, a nivel de políticas sociales, económicas y, cómo no, ambientales. Y es precisamente en las secuelas de eventos tan disruptivos que la inmuno-biopolítica del Antropoceno puede realizar su trabajo más obsceno, la promesa imposible de que la "humanidad" podría de hecho manejar el sistema terrestre o incluso los ecosistemas locales sin alterar la matriz de las relaciones socioecológicas existentes (Swyngedow y Ernstson, 2018, p. 22).

\section{Conclusiones}

Le Billon (2015, p. 600) recoge, rehaciéndose a las teorías de Robbins, dos facetas principales en las tesis del conflicto ambiental, según las cuales la apropiación de los recursos por parte de autoridades estatales, empresas privadas o élites sociales generan tal escasez de éstos que el conflicto entre grupos (étnicos, de géneros y/o clase) se ve acelerado. Por un lado, cuando los problemas ambientales se "politizan" — esto es, cuando grupos locales aseguran el control de los recursos colectivos a expensas de otros al aprovechar las intervenciones de gestión de las autoridades de desarrollo, agentes estatales o empresas privadas-. Estas circunstancias se materializan en nuestro ámbito: las jerarquías chinas han ejercen un control estricto sobre el territorio per se -cual enclave geoestratégico- y sus recursos - gas, petróleo, minerales-, cuyos beneficios fomentan una creciente diferencia de clase y la gentrificación de la región a costa del desarrollo de los pueblos túrquicos autóctonos. 
Por otro lado, apunta Le Billon a la "ecologización" de conflictos preexistentes como resultado de "cambios en la política de conservación o desarrollo de recursos" (2015, p. 600), subrayando los procesos de apropiación asimétricas y distribuciones desiguales del acceso a éstos. Apropiación a lo largo de este texto se ha entendido, en los términos de Jason Moore $(2015, \mathrm{p} .17)$ como todos aquellos procesos que identifican, aseguran y canalizan el trabajo no pagado fuera del sistema de commodities, y en el circuito del capital. La apropiación que la RPCh ejerce sobre la tierra y las gentes de XUAR, a la vez que los desposee, los relega en una posición subalterna en los mecanismos de esa "modernidad socialista" a la que el gobierno propugna aspirar.

Martínez-Alier (200I, p. I6I) considera que, en el Tercer Mundo - ese Tercer Mundo que se constituye en Bandung, precisaríamos aquí- los problemas de justicia ambiental han surgido principalmente respecto de la defensa de los recursos de propiedad común contra el estado o el mercado. Sin ánimo de discutir acerca de la "comunalidad" de las formas de manejo autóctonas de las poblaciones túrquicas antes de la conquista china, el "estado" y el "mercado" representan en nuestro caso los dos grandes actores que promueven, gracias a los tentáculos ambientales de su colonialidad, una geopolítica de la dominación en el territorio. Las consecuencias de ésta se materializan en un verdadero ecocidio ${ }^{14}$.

Se hace pues tarea necesaria, como también proponen Andrés Fabián Henao Castro y Henrik Ernstson (2019), desarrollar relatos situados de las luchas contra las condiciones de exclusión. Pero más allá de eso, también debemos construir investig-acciones que relancen la performatividad política de las experiencias subalternas.

La tierra, el espacio que se habita, las formas de manejo de ésta de las comunidades, por lo tanto, adquieren en este contexto un valor epistemológicamente digno y desjerarquizado, que influye en la manera de concebir y de autoconcebirse como comunidad.

"Los chinos nunca nos considerarán chinos, pero tampoco nunca nos dejarán ser uigures. Hay un desconocimiento peligroso de las minorías, y están intentando promover una asimilación forzada aunque sea ineficiente: la gente normal no nos verá nunca como si fuésemos parte de su pueblo.Yo no quiero decir que soy de Turkestán Oriental, porque no es un país, no existe en realidad. Pero tampoco quiero decir que soy china, porque no me siento china... Pese a tener papeles chinos, por lo que oficialmente lo soy" (entrevistada 4, comunicación personal confidencial a la autora).

La colonización y los mecanismos de la colonialidad han impuesto unos cambios en las formas de manejo y de relacionarse con el entorno natural, convirtiendo a "ecosistemas particulares" en "formas modernas de la naturaleza" (Escobar, 2000). Puesto que las formas de vivir de los colectivos subalternos, en todos sus aspectos, se someten al modelo moderno/colonial, es

14 Tomo prestada la palabra y el concepto de Antonio Ortega Santos, como muchos y muchas decoloniales españoles y españolas estamos empezando a hacer, en nuestras definiciones-descripciones del Sistema-Mundo actual. Cfr. Ortega Santos, A. (20I5). Diálogo de saberes ambientales entre Europa-América. Agroecosistemas oasianos en Baja California Sur s. XVIII-XX. Asclepio, 67 (I), p. 76. https://doi:I0.3989/asclepio.20I5.02 (I I.08.2020). 
preciso volver a dignificar los intentos comunitarios de supervivencia y resistencia, vivificando el medio ambiente como uno más de los sujetos oprimidos por los mecanismos de la Modernidad capitalista. El eje socioambiental de la perspectiva decolonial sugiere participar en la formulación de alternativas para generar, a través de una investigación comprometida y apoyada en una praxis decolonial, propuestas reales para reivindicar la deuda histórica de la colonización en los conflictos y problemas socioambientales, y que desde el Sur y los diferentes contextos en los que vivimos manifiesta la necesidad de cooperar para una(s) sociedad(es) más justa(s) y contra todas las opresiones:"sin embargo, al abrazar radicalmente las exterioridades del mundo socio-natural, sabemos por la historia y la experiencia cotidiana que quedan formas más igualitarias de ser-encomún están por realizar" (Swyngedow y Ernstson, 2018, p. 23).

\section{Referencias}

Agnew, J. (2010). Emerging China and Critical Geopolitics: Between World Politics and Chinese Particularity. Eurasian Geography and Economics, 5 I (5), 569-582. https://doi.org/I0.2747/I539-72I6.5I.5.569

ALICE CES (18.07.20I6). Alice na cidade: Ciências Sociais, Rap e Mais - Intervenção de Banda Linha Abissal [Video file] Recuperado de: https://www.youtube.com/watch?v=PeGpZyllakw (a partir del minuto 8:30) (25.05.2018).

Anand, D. (2019). Colonization with Chinese characteristics: politics of (in)security in Xinjiang and Tibet. Central Asian Survey, 38 (I), 129-147

Anderson, B. (200I).Western nationalism and eastern nationalism: Is there a difference that matters? New Left Review, 2I, 3I-42.

Ascensão, F., Fahrig, L., Clevenger, A.P., Corlett, R.T., Jaeger, J.A.G., Laurance,W.F., y Pereira, H.M. (20I8). Environmental challenges for the Belt and Road Initiative. Nature Sustainability, I, 206-209. https://doi.org/I0.1038/s4/893018-0059-3

Asia-Africa speak from Bandung. (1955) Djakarta:The Ministry of Foreign Affairs Republic of Indonesia.

Bellér-Hann, I. (1997). The peasant condition in Xinjiang. The Journal of Peasant Studies, 25 (I), 87-II2. https://doi. org//0.1080/03066/59708438659

Campaign For Uyghurs (2020). China's genocide in East Turkestan. The Genocide of Uyghurs by Definition of the United Nation Convention on Genocide Prevention. Recuperado de: https://campaignforuyghurs.org/wp-content/ uploads/2020/07/Genocide-Report-English-I.pdf (I0.08.2020).

Castro-Gómez, S., y Grosfoguel, R. (Eds.) (2007). El giro decolonial: reflexiones para una diversidad epistémica más allá del capitalismo global. Siglo del Hombre Editores.

China Daily (07.05.20 I7). What's the Belt and Road Initiative? - "Belt and Road Bedtime Stories" series episode I [Video file]. Recuperado de: https://www.youtube.com/watch?v=uKhYFFLBaeQ\&feature=youtu.be (26.08.2019)

Chomsky, N. (2016). ¿Quién domina el mundo? Penguin Random House.

Clarke, M. (2007). The Problematic Progress of 'Integration' in the Chinese State's Approach to Xinjiang, 1759-2005. Asian Ethnicity, 8 (3), 26I-289. https://doi.org//0.1080//463 I36070I5950I5

Clarke, M. (2017). The Belt and Road Initiative and China's Xinjiang Dilemma: 'Connectivity' Versus Control? The Central Asia-Caucasus ANALYST. https:/www.cacianalyst.org/publications/analytical-articles/ item/I 3458-the-belt-and-road-initiative-and-china's-xinjiang-dilemma-"connectivity"-versus-control?.html

Cliff, T. (2009). Neo Oasis:The Xinjiang Bingtuan in the Twenty-first Century. Asian Studies Review, 33 (I), 83-106. https://doi.org// 0.1080//03578208027/4807.

Crosby, A. (1988). Imperialismo Ecológico La expansión biológica de Europa, (900-1900). Editorial Crítica.

Escobar,A. (2000). El lugar de la naturaleza y la naturaleza del lugar: iglobalización o postdesarrollo? En Lander, E. (Ed). La colonialidad del saber: Eurocentrismo y ciencias sociales. Perspectivas latinoamericanas (pp. 68-87). CLACSO Consejo Latinoamericano de Ciencias Sociales.

Escobar,A. (2016). Sentipensar con la Tierra: Las Luchas Territoriales y la Dimensión Ontológica de las Epistemologías del Sur. AlBR - Revista Iberoamericana de Antropología, I I (I), I I-36. https://doi:I0.I I I56/aibr. I 0102

Frankopan, P. (2018). The New Silk Roads. Bloomsbury Publishing.

Golden, P. (2006). Some thoughts on the origins of the Turks and the shaping of the Turkic peoples. En Mair, V. (Ed). Contact and Exchange in the Ancient World (pp. 136-157). University of Hawai'i Press.

Grose, T. (I I.08.2020). Publicación de Timothy Grose en su cuenta de Twitter. Recuperado de: https://twitter.com/ GroseTimothy/status/ I 293375 | 84674664448?s=20 (I I.08.2020)

Grosfoguel, R. (2008). Para descolonizar os estudos de economia política e os estudos pós-coloniais:Transmodernidade, pensamento de fronteira e colonialidade global. Revista Crítica de Ciências Sociais, 80, II5-147. https:// doi.org/ $/ 0.4000 /$ rccs.697

Gudynas, E. (20 I6). Teología de los extractivismos. Tabula Rasa, 24, I I-23. https://doi.org/ I0.25058/20 I I2742.55 
Islam, Md. Nazrul (Ed). (2019). Silk Road to Belt Road. Reinventing the Past and Shaping the Future. Springer.

Jacobs, J.M. (2016). Xinjiang and the Modern Chinese State. University of Washington Press.

Johnson, C.K. (2016). President Xi Jinping's "Belt and Road" Initiative.A Practical Assessment of the Chinese Communist Party's Roadmap for China's Global Resurgence. CSIS - Center for Strategic and International Studies.

Henao Castro, A.F. y Ernstson, H. (2019). "Hic Rhodus, Hic Salta!” Postcolonial Remains and the Politics of the Anthropo-ob(S)cene. En Ernstson, H. y Swyngedouw, E. (Eds). Urban Political Ecology in the Anthropo-obscene: Interruptions and Possibilities (pp. 69-87). Routledge.

Inquérito (29.I I.2018). INQUÉRITO e Boaventura de Sousa Santos | Linha Abissal [Video file]. Recuperado de: https:// www.youtube.com/watch?v=AlHnMgu_Hys (30.1I.20I8).

Le Billon, P. (20I5). Environmental conflict. En Perreault, T., Bridge, G. y McCarthy, J. (Eds). The Routledge Handbook of Political Ecology (pp. 598-608). Routledge.

Leibold, J. (2007). Reconfiguring Chinese Nationalism: How the Qing Frontier and Its Indigenes Became Chinese. Palgrave Macmillan.

Martínez Alier, J. (20I I). El ecologismo de los pobres: conflictos ambientales y lenguajes de valoración. Icaria.

McNeill, J. (26.02.2019). Anthropocene. Recuperado de: https://www.kth.se/en/abe/inst/philhist/historia/ehl/ehl-dictionary/anthropocene-john-mcneill-I.499858 (05.08.2020).

Meneses, M.P. (2020). Desafios ambientais a Sul: o ubuntu como ética de ligação entre a comunidade e a natureza. En Ortega Santos, A. y Olivieri, C. (Eds). Saberes bioculturales. En pie de resistencias desde el Sur Global (pp. 49-8I). Editorial Universidad de Granada.

Mignolo, W. (2000). Border Thinking and the Colonial Difference. En Mignolo, W. (Ed). Local Histories/Global Designs: Coloniality, Subaltern Knowledges and Border Thinking (pp. 49-90). Princeton UniversityPress.

Millward, J. (2009). Positioning Xinjiang in Eurasian and Chinese history: differing Visions of the 'Silk Road'. En Clarke, M. y Mackerras, C. (Eds). China, Xinjiang and Central Asia: History, Transition and Future Prospects into the 2 Ist Century (pp. 55-74). Routledge.

Millward, J.A. (marzo, 2018). Old World Geoschemes, Past and Present, and the Belt and Road Initiative as Sino-Silk Roadist Remapping of Afro-Eurasia.Trabajo presentado en Remapping Asian Studies, Granada.

Millward, J.A. (202I). Eurasian Crossroads. A History of Xinjiang. Hurst Publishers

Moore, J. (2015). Capitalism in the Web of Life: Ecology and the Accumulation of Capital.Verso.

New China TV (I0.05.20I7a). Music Video:The Belt and Road is How [Video file]. Recuperado de: https://www.youtube. com/watch?v=M0lJc3PMNlg (26.08.20I9).

New China TV (14.05.20 I7b). Music Video:The Belt and Road, Sing Along [Video File]. Recuperado de: https://www. youtube.com/watch? $v=98 R$ Nh7rwyf8 (26.08.2019).

OECD. The Belt and Road Initiative in the global trade, investment and finance landscape. OECD Business and Finance Outlook, 6I-I0I.https://doi.org/10.I787/bus fin out-2018-6-en

Oidtmann, M. (2018). Forging the Golden Urn:The Qing Empire and the Politics of Reincarnation in Tibet. Columbia University Press

Olivieri, C. (0I.04.20 I9).Asia. Dicionário Alice. Recuperado de: https://alice.ces.uc.pt/dictionary/?id=23838\&pag=239 I 8 \&id_lingua= I\&entry=24598 (05.08.2020).

Olivieri, C. y Ortega Santos, A. (2020). Not only Deserts, Not Only Oases. Territorial Identities in Baja California (Mexico) and Xinjiang (China) in the Contemporary Age. Global Humanities, 5 (7), 27-43.

Ortega Santos, A. y Olivieri, C. (Eds) (2020). Saberes bioculturales. En pie de resistencias desde el Sur Global. Editorial Universidad de Granada.

Qarluq, A.i.J., y McMillen, D.H. (20I I). Towards a 'Harmonious Society'? a brief case study of the post-Liberation settlement in Beijing of Uyghur intellectuals and their relations with the majority society. Asian Ethnicity, I2 (I), I-3I. https://doi.org/I0.1080/|4631369.2010.510876

Peña Romulo, C. (1956). The Meaning of Bandung. The University of North Carolina Press.

Pérez García, M. (20I4). From Eurocentrism to Sinocentrism: New Challenges in Global History. European Journal of Scientific Research, II9 (3), 337-352.

Regional Ethnic Autonomy Law of the People's Republic of China. ( 1 984). Recuperado de: https://www.cecc.gov/resources/legal-provisions/regional-ethnic-autonomy-law-of-the-peoples-republic-of-china-amended (06.08.2020).

Restrepo, E. (2016). Descentrando a Europa: aportes de la teoría postcolonial y el giro decolonial al conocimiento situado. Revista Latina de Sociología, 6, 60-7I. https://doi: I 0.I7979/relaso.20 I6.6.I.1965

Roberts, S. R. (2020). The War on the Uyghurs: China's Campaign Against Xinjiang's Muslims. Princeton University Press.

Santos, B. d. S. (2005). Desigualdad, Exclusión y Globalización: Hacia la Construcción Multicultural de la Igualdad y la Diferencia. Revista de Interculturalidad, I, 9-44

Santos, B. d. S. (2007). Para além do Pensamento Abissal: Das linhas globais a uma ecologia de saberes. Revista Crítica de Ciências Sociais, 78, 3-46. https://doi.org/I0.4000/rccs.753

Santos, B. d. S. (2010a). Descolonizar el saber, reinventar el poder. Ediciones Trilce.

Santos, B. d. S. (20lOb). From the Postmodern to the Postcolonial - and Beyond Both. En Gutiérrez Rodríguez, E., Boatcă, M., Costa, S. (Eds.), Decolonizing European Sociology.Transdisciplinary Approaches (pp. 225-242). Ashgate.

Santos, B. d. S. (20I2). De las dualidades a las ecologías. Cuaderno de Trabajo, I 8, I3-32.

Santos, B. d. S. (20I4). Derechos humanos, democracia y desarrollo. Centro de Estudios de Derecho, Justicia y Sociedad, Dejusticia. 
Santos, B. d. S., y Meneses, M. P. (Eds.). (2014). Epistemologías del Sur. Perspectivas. Ediciones Akal.

Sautman, B. (2000). Is Xinjiang an Internal Colony? Inner Asia, 2 (2), 239-27 I. https://doi: I 0. I I 63/ I 4648 I 700793647788

Steinmetz, G. (2014). The Sociology of Empires, Colonies, and Postcolonialism. Annual Review of Sociology, 40, 77-I03. https://doi.org/I0.II46/annurev-soc-07|9|3-043I3I

Suárez-Krabbe, J. (0I.04.2019). Modernity. Dicionário Alice. Recuperado de: https://alice.ces.uc.pt/dictionary/?id=23838 \&pag=239|8\&id_lingua=4\&entry=24325 (I I.08.2020).

Summers, T. (2016). China's 'New Silk Roads': sub-national regions and networks of global political economy. Third World Quarterly, 37 (9), I.628-I.643. https://doi.org/10.1080/01436597.2016.1 I534I5

Swyngedouw, E.y Ernstson, H. (2018). Interrupting the Anthropo-obScene: Immuno-bioploitics and Depoliticizing Ontologies in theAnthropocene. Theory, Culture \& Society, 35 (6), 3-30.https://doi.org/ I 0. I I 77/02632764 I87573 I 4

The World Bank (29.03.20I8). Belt and Road Initiative. Recuperado de: https://www.worldbank.org/en/topic/regionalintegration/brief/belt-and-road-initiative (06.08.2020).

Thum, R. (20 I2). Modular History: Identity Maintenance before Uyghur Nationalism. The Journal of Asian Studies, 7I (3), 627-653. https://doi:10.1017/S0021911812000629

Vergès, F. (2017). Racial Capitalocene. En Johnson, G.T. (Ed). Futures of Black Radicalism (pp. 72-82). Verso.

Yoon, D.M. (2018). Bandung Nostalgia and the Global South. En West-Pavlov, R. (Ed). The Global South and Literature (pp. 23-33). Cambridge University Press. 


\section{RELACIONES INTERNACIONALES}

Revista académica cuatrimestral de publicación electrónica

Grupo de Estudios de Relaciones Internacionales (GERI)

Universidad Autónoma de Madrid, España

https://revistas.uam.es/relacionesinternacionales

ISSN 1699 - 3950

f facebook.com/RelacionesInternacionales

3. twitter.com/RRInternacional 